\title{
Effects of Angiotensin-converting Enzyme Inhibitors and Angiotensin II Type 1 Receptor Antagonists in Rats with Heart Failure

\author{
Role of Kinins and Angiotensin II Type 2 Receptors
}

Yun-He Liu, Xiao-Ping Yang, Victor G. Sharov, ${ }^{\star}$ Omar Nass, ${ }^{*}$ Hani N. Sabbah, ${ }^{*}$ Edward Peterson, ${ }^{\ddagger}$ and Oscar A. Carretero

Hypertension and Vascular Research Division, *Division of Cardiovascular Medicine, Heart and Vascular Institute and Department of

Medicine, and ${ }^{\ddagger}$ Division of Biostatistics and Research Epidemiology, Henry Ford Hospital, Detroit, Michigan 48202

\begin{abstract}
Angiotensin-converting enzyme inhibitors (ACEi) improve cardiac function and remodeling and prolong survival in patients with heart failure (HF). Blockade of the renin-angiotensin system (RAS) with an angiotensin II type 1 receptor antagonist ( $\mathrm{AT}_{1}$-ant) may have a similar beneficial effect. In addition to inhibition of the RAS, ACEi may also act by inhibiting kinin destruction, whereas $\mathrm{AT}_{1}$-ant may block the RAS at the level of the $\mathrm{AT}_{1}$ receptor and activate the angiotensin II type 2 ( $\left.\mathrm{AT}_{2}\right)$ receptor. Using a model of $\mathrm{HF}$ induced by myocardial infarction (MI) in rats, we studied the role of kinins in the cardioprotective effect of ACEi. We also investigated whether an $\mathrm{AT}_{1}$-ant has a similar effect and whether these effects are partly due to activation of the $\mathrm{AT}_{2}$ receptor. Two months after MI, rats were treated for 2 mo with: $(a)$ vehicle; $(b)$ the ACEi ramipril, with and without the $B_{2}$ receptor antagonist icatibant $\left(B_{2}\right.$-ant); or $(c)$ an $A_{1}$ ant with and without an $\mathrm{AT}_{2}$-antagonist ( $\mathrm{AT}_{2}$-ant) or $\mathrm{B}_{2}$ ant. Vehicle-treated rats had a significant increase in left ventricular end-diastolic (LVEDV) and end-systolic volume (LVESV) as well as interstitial collagen deposition and cardiomyocyte size, whereas ejection fraction was decreased. Left ventricular remodeling and cardiac function were improved by the ACEi and $\mathrm{AT}_{1}$-ant. The $\mathrm{B}_{2}$-ant blocked most of the cardioprotective effect of the ACEi, whereas the effect of the $\mathrm{AT}_{1}$-ant was blocked by the $\mathrm{AT}_{2}$-ant. The decreases in LVEDV and LVESV caused by the $\mathrm{AT}_{1}$-ant were also partially blocked by the $\mathrm{B}_{2}$-ant. We concluded that $(a)$ in $\mathrm{HF}$ both $\mathrm{ACEi}$ and $\mathrm{AT}_{1}$-ant have a cardioprotective effect, which could be due to either a direct action on the heart or secondary to altered hemodynamics, or both; and (b) the effect of the ACEi is mediated in part by kinins, whereas that of the $\mathrm{AT}_{1}$-ant is triggered by activation of the $\mathrm{AT}_{2}$ receptor and is also mediated in part by kinins. We speculate that in $\mathrm{HF}$, blockade of $\mathrm{AT}_{1}$ receptors increases both renin and angiotensins; these angiotensins stimulate the $\mathrm{AT}_{2}$ receptor, which in turn may play an important role in the therapeutic effect of the $\mathrm{AT}_{1}$-ant via kinins and other
\end{abstract}

Address correspondence to Oscar A. Carretero, Division Head, Hypertension and Vascular Research Division, Henry Ford Hospital, 2799 West Grand Blvd., Detroit, MI 48202-2689. Phone: 313-876-2103; FAX: 313-876-1479.

Received for publication 1 November 1996 and accepted in revised form 27 January 1997.

J. Clin. Invest.

(C) The American Society for Clinical Investigation, Inc.

0021-9738/97/04/1926/10 \$2.00

Volume 99, Number 8, April 1997, 1926-1935 autacoids. (J. Clin. Invest. 1997. 99:1926-1935.) Key words: angiotensin-converting enzyme $\cdot$ angiotensin II type 1 and 2 receptors $\bullet$ kinins $\bullet$ kinin antagonist $\bullet$ chronic heart failure

\section{Introduction}

Angiotensin-converting enzyme inhibitors (ACEi) ${ }^{1}$ improve cardiac function and remodeling and prolong survival in patients with heart failure (HF) (1-7). The cardioprotective effect of ACEi may be due to blockade of the renin-angiotensin system and/or inhibition of kinin destruction $(6,8,9)$. We and others have provided evidence that kinins mediate many of the cardiovascular effects of ACEi (8,10-14). On the other hand, there is some evidence that angiotensin II type 1 receptor $\left(\mathrm{AT}_{1}\right)$ antagonists improve cardiac function in $\mathrm{HF}$ (15-18). Thus, since both $\mathrm{ACEi}$ and $\mathrm{AT}_{1}$ antagonists $\left(\mathrm{AT}_{1}\right.$-ant) block the renin-angiotensin system at different levels and both have a cardioprotective effect, we may interpret these data as implying that the cardioprotective effect of ACEi is due to blockade of the conversion of angiotensin I to II, not inhibition of kinin hydrolysis. However, the effect of the $\mathrm{AT}_{1}$-ant may not be entirely due to blockade of the $\mathrm{AT}_{1}$ receptor. Angiotensin receptors comprise two major subtypes, $\mathrm{AT}_{1}$ and $\mathrm{AT}_{2}$ (19). When the $\mathrm{AT}_{1}$ receptor is blocked, plasma renin and angiotensins increase (20); angiotensin may act on $\mathrm{AT}_{2}$ receptors, which could have an antitrophic effect $(21,22)$ either directly or via the release of autacoids such as kinins and nitric oxide (NO) $(23,24)$ and consequently may contribute to the therapeutic effect of $\mathrm{AT}_{1}$-ant by a mechanism similar to kinins. Therefore, we tested the hypothesis that in HF the chronic therapeutic effect of ACEi is mediated in part by kinins, while the effect of $\mathrm{AT}_{1}$ ant is due to not only blockade of the $\mathrm{AT}_{1}$ receptor but also activation of the $\mathrm{AT}_{2}$ receptor. We also tested the hypothesis that some of the effects of the $\mathrm{AT}_{1}$-ant are mediated in part by kinins, perhaps via activation of the $\mathrm{AT}_{2}$ receptor.

To test this hypothesis, we used a model of HF induced by myocardial infarction (MI) in Lewis inbred rats, developed by us (25). In this strain, ligation of the left anterior descending

1. Abbreviations used in this paper: $\mathrm{ACE}$, angiotensin-converting enzyme; $\mathrm{ACEi}$, angiotensin-converting enzyme inhibitor; $\mathrm{AT}_{1}$, angiotensin II type 1 receptor; $\mathrm{AT}_{1}$-ant, angiotensin II type 1 receptor antagonist; $\mathrm{AT}_{2}$, angiotensin II type 2 receptor; $\mathrm{AT}_{2}$-ant, angiotensin II type 2 receptor antagonist; $B_{2}$-ant, $B_{2}$ receptor antagonist; EDV, enddiastolic volume; $\mathrm{EF}$, ejection fraction; $\mathrm{ESV}$, end-systolic volume; $\mathrm{HF}$, heart failure; HR, heart rate; LAD, left anterior descending coronary artery; LV, left ventricle; LVEDP, left ventricular end-diastolic pressure; LVEDV, left ventricular end-diastolic volume; LVEF, left ventricular ejection fraction; LVESV, left ventricular end-systolic volume; MI, myocardial infarction; NO, nitric oxide; RAS, reninangiotensin system. 
coronary artery (LAD) produces uniformly large infarcts with low mortality compared to Sprague-Dawley rats. In addition, 2 mo after MI both ventricular volume and end-diastolic pressure are significantly increased while the ejection fraction (EF) is decreased. To assess LV dilation and performance, we use a direct angiographic method also developed by us (26). Using this model of HF, we investigated $(a)$ whether the ACEi ramipril improves cardiac function and reduces ventricular remodeling; (b) whether the kinin antagonist icatibant (Hoe 140; D-Arg[ $\left[\mathrm{Hyp}^{3}, \mathrm{Thi}^{5}, \mathrm{D}-\mathrm{Tic}^{7}, \mathrm{Oic}^{8}\right]$-bradykinin) blocks the beneficial effect of ramipril; $(c)$ whether the $\mathrm{AT}_{1}$-ant $\mathrm{L} 158809$ improves cardiac function and reduces ventricular remodeling; $(d)$ whether the $\mathrm{AT}_{2}$-ant PD123319 blocks the effect of the $\mathrm{AT}_{1}$ ant; and $(e)$ whether icatibant blocks the effect of the $\mathrm{AT}_{1}$-ant.

\section{Methods}

Male Lewis inbred rats (Charles River Laboratories, Wilmington, MA) weighing 275-330 grams were housed in an air-conditioned room with a 12 -h light/dark cycle; they received standard laboratory rat chow ( $0.4 \%$ sodium) and drank tap water. Animals were given 5-7 d to adjust to their new environment. The study was approved by the Henry Ford Hospital Care of Experimental Animals Committee. Rats were anesthetized with sodium pentobarbital for all surgical procedures $(50 \mathrm{mg} / \mathrm{kg}$ i.p.).

Experimental heart failure model. Coronary ligation was performed as described previously $(25,26)$. The animals were intubated and ventilated with room air using a positive-pressure respirator (680; Harvard Apparatus Inc., South Natick, MA). A left thoracotomy was performed via the fourth intercostal space and the lungs retracted to expose the heart. After opening the pericardium, the LAD was ligated near its origin using a 7-0 silk suture. Coronary ligation was considered successful when the anterior wall of the LV turned pale. The lungs were inflated by increasing positive end-expiratory pressure and the thoracotomy site closed in layers. Another group of rats underwent sham ligation; they had a similar surgical procedure except that the suture was not tightened around the coronary artery. In a previous study using the same model, we showed that the ejection fraction (EF) was decreased from $61-63 \%$ in sham-infarcted Lewis rats to 34,31 , and $24 \%$ at 2, 4 and 6 mo after MI, while LV end-diastolic volume (EDV) and end-systolic volume (ESV) were increased at least twofold at 2 mo after MI (25). Accordingly, all studies were performed starting 2 mo after MI.

Experimental protocols. 2 mo after sham or coronary ligation, the rats were divided into six groups and treated for 2 mo. Groups 7, 8, and 9 were studied in a subsequent experiment after we found that the $\mathrm{AT}_{1}$-ant has a cardioprotective effect.

Protocol 1: role of kinins in the effect of ACEi. Groups: (a) sham LAD ligation $(n=10) ;(b) \mathrm{HF}$ treated with vehicle (tap water) $(n=$ 10); (c) HF treated with ramipril (1 mg/kg/day; donated by Upjohn Laboratories, Kalamazoo, MI) $(n=9) ;(d)$ HF treated with ramipril + icatibant $(100 \mu \mathrm{g} / \mathrm{kg}$ per day via an osmotic pump) $(n=11)$; and (e) HF treated with icatibant alone (donated by Hoechst, Cincinnati, $\mathrm{OH})(n=9)$.

Protocol II: role of $A T_{2}$ receptors and kinins in the effect of $A T_{1^{-}}$ ant. Groups: $(f)$ HF treated with the $\mathrm{AT}_{1}$-ant L-158809 $(1.5 \mathrm{mg} / \mathrm{kg}$ per day) $(n=8) ;(g)$ HF treated with $\mathrm{AT}_{1}$-ant + the $\mathrm{AT}_{2}$-ant PD123319 $(10 \mathrm{mg} / \mathrm{kg}$ via an osmotic pump $)(n=7) ;(h) \mathrm{HF}$ treated with $\mathrm{AT}_{1}$-ant + icatibant $(n=7)$; and $(i) \mathrm{HF}$ treated with $\mathrm{AT}_{2}$-ant $(n=7)$.

Cardiac hemodynamics and ventriculography. 2 mo after initiating therapy (4 mo after sham ligation or MI), the rats were anesthetized and a polyethylene catheter (PE-50) inserted into the carotid artery. Mean BP and heart rate (HR) were measured with a P23XL pressure transducer connected to a processor (Gould Brush 220, Cleveland, $\mathrm{OH})$. The carotid catheter was then advanced into the LV; ventricular pressures were measured, and ventriculograms obtained and recorded on 35-mm ciné film at 60 frames/s during injection of 0.5 $\mathrm{ml}$ contrast material (Reno-M-60; Squibb, New Brunswick, NJ). The films were projected and the margins of the LV silhouette traced during end-diastole and end-systole for three consecutive cardiac cycles (26). End-systolic volume (ESV) and end-diastolic volume (EDV) were determined using the area-length method (27). LV ejection fraction $(\mathrm{LVEF})$ was calculated as $\mathrm{EF}=(\mathrm{EDV}-\mathrm{ESV}) / \mathrm{EDV}$.

Histopathological study. After the hemodynamic and ventriculographic studies, the rats were killed and the chest opened. The heart was excised and weighed and the LV sectioned transversely into four slices from apex to base. The slices were rapidly frozen in isopentane precooled in liquid nitrogen, and stored at $-70^{\circ} \mathrm{C}$. $10-\mu \mathrm{m}$ sections were cut from each frozen slice and stained separately with $(a)$ fluorescein-labeled peanut agglutinin (Vector Laboratories, Inc., Burlingame, CA) after pretreatment with $3.3 \mathrm{U} / \mathrm{ml}$ neuroaminidase type $\mathrm{V}$ (Sigma Chemical Co., St. Louis, MO) to delineate myocyte cross-sectional area (an indicator of myocyte volume) and the interstitial space (consisting of collagen and capillaries); (b) rhodamine-labeled Griffonia simplicifolia lectin I (GSL I) to show only the capillaries, since GSL I selectively binds to capillaries (28, 29); and (c) Masson's trichrome for measurement of infarct size. Three radially oriented microscopic fields were selected from each section randomly and photographed on 35-mm film at a magnification of 100. Only noninfarcted regions of the LV were examined for histopathological study (except for infarct size).

Cardiomyocyte cross-sectional area. Images were projected with a photomagnifier. Cross-sectional area of each myocyte was measured by computer-based planimetry (Jandel, Corte Madera, CA). An average cross-sectional area was calculated using data obtained from all four slices.

Interstitial collagen fraction. Total surface area (microscopic field), interstitial space (collagen plus capillaries) and area occupied by capillaries alone were measured with computer-assisted videodensitometry (JAVA; Jandel). Interstitial collagen fraction was calculated by percent total surface area occupied by the interstitial space minus the percent total surface area occupied by the capillaries. An average interstitial collagen fraction was calculated using data obtained from all four slices.

Capillary density and oxygen diffusion distance. Capillary density was taken as the number of capillaries in a given microscopic field (expressed as number of capillaries $/ \mathrm{mm}^{2}$ ), since morphometric results obtained with light microscopy do not provide sufficient resolution for an accurate count of myocyte numbers, and thus we were unable to measure the ratio of capillary density to number of myocytes (capillaries per myocyte). Oxygen diffusion distance was calculated as half the distance between two adjoining capillaries (30). Average capillary density and oxygen perfusion distance were calculated using data obtained from all four slices.

Myocardial infarct size. Sections were projected on a graphic master. The circumference of the entire endocardium and epicardium as well as the infarcted segment were measured by computer-assisted planimetry. Circumferences from all four slices (entire endocardium and epicardium as well as the infarcted portion) were added together and averaged, respectively. The infarcted portion of the LV was calculated from these measurements and expressed as a percentage of the total circumference $(25,26)$.

Data analysis. All data are expressed as mean \pm SEM. The data were analyzed in two separate sets, protocol 1 and protocol 2, although they shared the same vehicle and sham groups. Analysis was primarily directed at a set of pairwise comparisons. To be conservative, we examined all pairwise comparisons using ANOVA based on Tukey's method. This approach adjusts the individual test rejection level downward to maintain an overall or familywise alpha value of 0.05 . It uses an estimate of pooled variance from all groups in the procedure. Statistical significance was defined as familywise $P<0.05$, which implies that the individual test level of $P$ is smaller. The data were evaluated for normality and equal variance structure and both assumptions were satisfied. 
Table I. Effect of ACEi or ACEi Plus $B_{2}$ Kinin Antagonist (K-ant) on Body Weight, Hemodynamics, Ventricular Weight, Myocardial Infarct Size, Capillary Density, and Oxygen Diffusion Distance in Controls (sham) and Rats with Heart Failure

\begin{tabular}{|c|c|c|c|c|c|}
\hline & \multirow[b]{2}{*}{ Sham $(n=10)$} & \multicolumn{4}{|c|}{ Heart failure } \\
\hline & & Vehicle $(n=10)$ & $\operatorname{ACEi}(n=9)$ & ACEi + K-ant $(n=11)$ & K-ant $(n=9)$ \\
\hline BW (grams) & $498 \pm 12$ & $532 \pm 6$ & $481 \pm 4 *$ & $460 \pm 6^{*}$ & $479 \pm 11 *$ \\
\hline MBP (mmHg) & $121 \pm 2$ & $116 \pm 3$ & $100 \pm 2$ & $88 \pm 5^{*}$ & $97 \pm 7$ \\
\hline HR (beats/min) & $357 \pm 5$ & $346 \pm 9$ & $358 \pm 8$ & $353 \pm 9$ & $357 \pm 8$ \\
\hline LVEDP (mmHg) & $2.6 \pm 0.9$ & $9.5 \pm 2.0$ & $1.4 \pm 2.0$ & $13.1 \pm 1.7^{\ddagger}$ & $11.4 \pm 2.9$ \\
\hline LV/100 grams BW & $174 \pm 2$ & $198 \pm 7$ & $185 \pm 5$ & $187 \pm 4$ & $208 \pm 11$ \\
\hline RV/100 grams BW & $43 \pm 1$ & $61 \pm 6$ & $53 \pm 4$ & $54 \pm 3$ & $55 \pm 12$ \\
\hline IS (\%) & - & $37 \pm 1$ & $40 \pm 1$ & $39 \pm 2$ & $39 \pm 2$ \\
\hline Capillary density $($ No./mm²) & $1520 \pm 58^{*}$ & $905 \pm 46$ & $1299 \pm 51^{*}$ & $1032 \pm 71$ & $1137 \pm 74$ \\
\hline Oxygen diffusion distance $(\mu \mathrm{m})$ & $10.35 \pm 0.15 *$ & $13.43 \pm 0.6$ & $11.7 \pm 0.27 *$ & $12.75 \pm 0.3$ & $13.13 \pm 0.5$ \\
\hline
\end{tabular}

BW, body weight; MBP, mean blood pressure; RV, right ventricle; IS, infarct size. Each value represents the mean \pm SEM. ${ }^{*} P<0.05$ vs vehicle; ${ }^{\ddagger} P<0.05$ vs ACEi.

\section{Results}

Early and late mortality. Of the 88 rats that underwent coronary ligation, 11 died within $24 \mathrm{~h}, 4$ died within 1 or 2 mo after MI and 5 died within 3 or 4 mo after MI, for an overall mortality rate of $23 \%$. No rats in the sham-ligated group died.
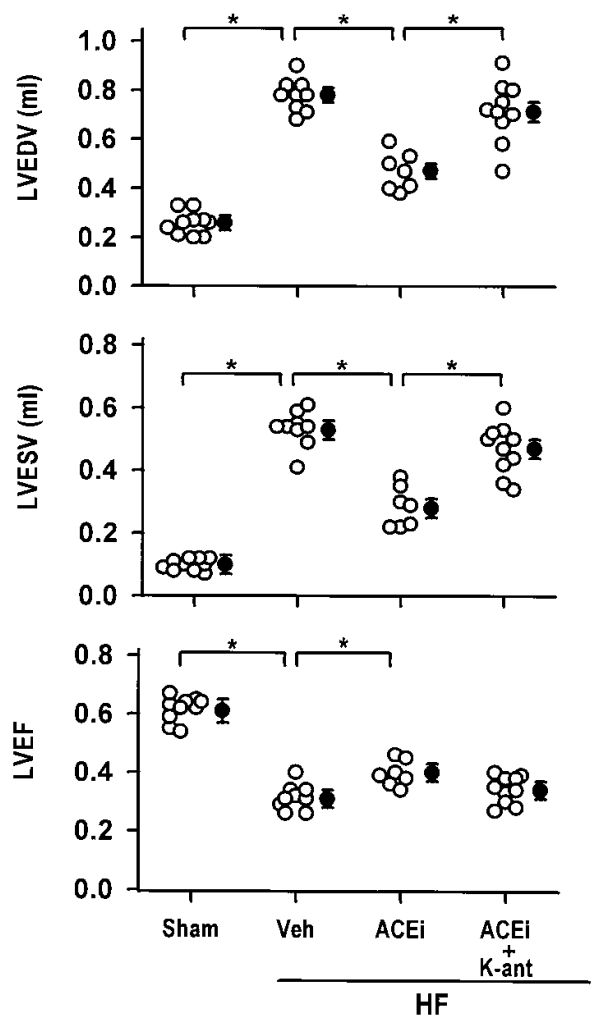

Figure 1. Effect of the angiotensin-converting enzyme inhibitor ramipril $(A C E i)$ and ACEi plus the kinin antagonist icatibant (K-ant) on left ventricular end-diastolic volume ( $L V E D V$, top), left ventricular end-systolic volume ( $L V E S V$, middle), and left ventricular ejection fraction $(L V E F$, bottom $)$ in sham-operated rats (Sham) and rats with chronic heart failure $(H F)$. Open circles, individual data; closed circles, mean values. $* P<0.05$. Veh, vehicle.
Protocol 1: Role of kinins in the effect of $A C E i$. Table I shows body weight, BP, HR, LV end-diastolic pressure (LVEDP), infarct size, and left and right ventricle weight as well as myocardial capillary density and oxygen diffusion distance for groups $a-e$. Icatibant did not prevent the effect of ramipril on BP; however, it did reverse the effect of ramipril on LVEDP.

Ventricular volume and ejection fraction. Fig. 1 shows LVEDV, LVESV, and LVEF in sham-ligated and HF rats. LVEDV and
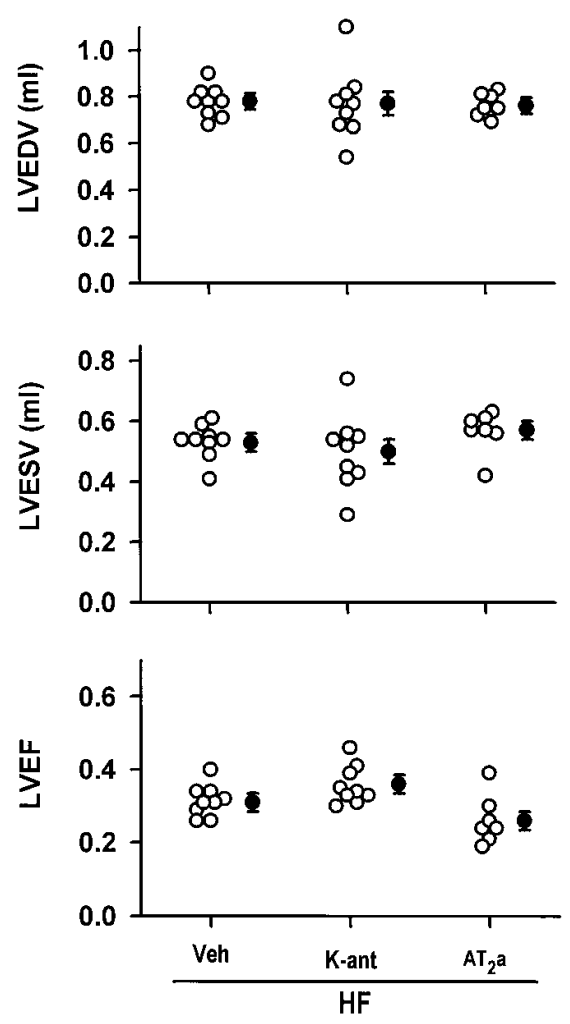

Figure 2. Effect of the kinin antagonist icatibant (K-ant) or the $\mathrm{AT}_{2}$ antagonist PD123319 $\left(A T_{2} a\right)$ on left ventricular end-diastolic volume ( $L V E D V$, top), left ventricular end-systolic volume ( $L V E S V$, middle) and left ventricular ejection fraction $(L V E F$, bottom $)$ in rats with chronic heart failure $(H F)$. Veh, vehicle. 

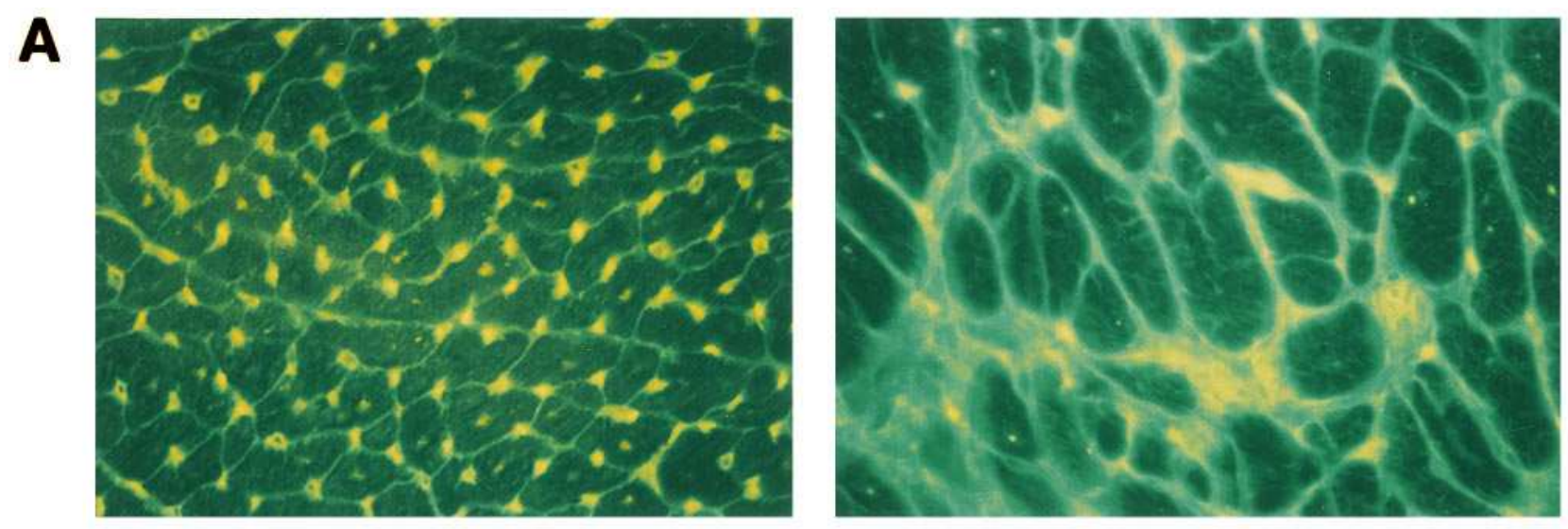

B
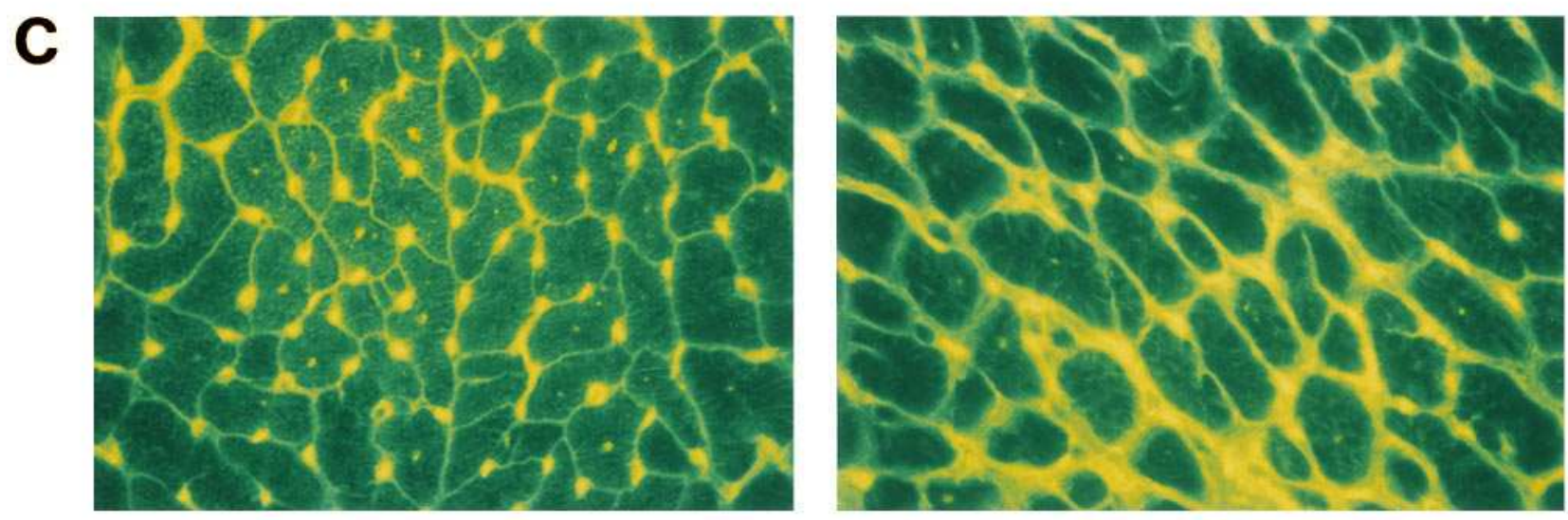

D
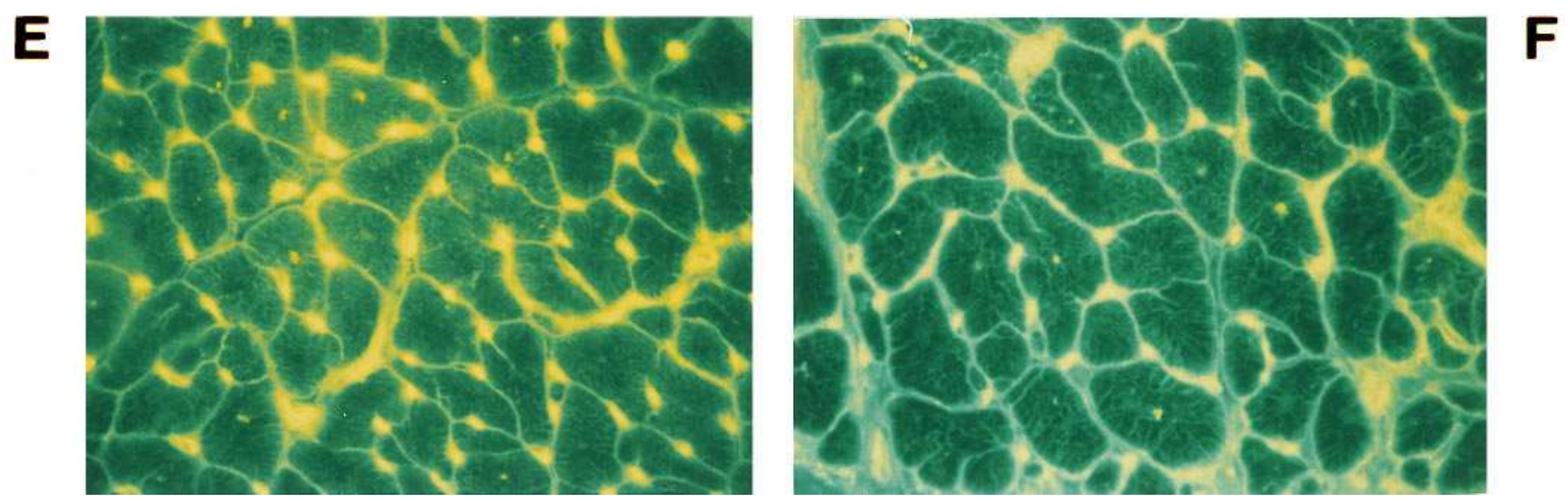

Figure 3. Representative histological sections of myocyte cross-sectional area, interstitial collagen deposition (green stained) and capillaries (yellow stained; since images were exposed under fluorescent light, the red color given by rhodamine is not apparent) from $(A)$ sham-ligated rats and HF rats treated with either $(B)$ vehicle, $(C)$ the angiotensin-converting enzyme inhibitor ramipril $(A C E i),(D)$ ACEi plus the $\mathrm{B}_{2}$ kinin antagonist icatibant, $(E) \mathrm{AT}_{1}$ antagonist $\left(A T_{1}\right.$-ant $)$ or $(F) \mathrm{AT}_{1}$-ant plus $\mathrm{AT}_{2}$-ant.

LVESV were significantly increased in the HF vehicletreated group compared with the sham-ligated rats (LVEDV: $0.78 \pm 0.02$ vs $0.26 \pm 0.01$; LVESV: $0.53 \pm 0.02$ vs $0.1 \pm 0.01 ; P<$ $0.05)$. Ramipril significantly decreased LVEDV $(0.47 \pm 0.03)$ and LVESV (0.28 \pm 0.02$)$ compared with the HF vehicle group $(P<0.05)$, and icatibant reversed this effect (LVEDV: 0.71 \pm 0.04 ; LVESV: $0.47 \pm 0.02 ; P<0.05$ vs ramipril).

LVEF was significantly decreased in the HF vehicle group compared with the sham-ligated rats $(0.31 \pm 0.01$ vs $0.61 \pm 0.01$; $P<0.05)$. Ramipril increased LVEF to $0.40 \pm 2.0(P<0.05)$ compared with $\mathrm{HF}$ vehicle. Icatibant tended to reverse the ef- fect of ramipril, but the difference was not statistically significant. In the HF group treated with icatibant alone, LVEDV, LVESV, and LVEF were no different than the HF vehicle group (Fig. 2).

Fig. 3 shows representative histological sections of myocyte cross-sectional area, interstitial collagen deposition, and capillaries from sham-ligated and HF rats treated with various drugs.

Cardiomyocyte cross-sectional area. Fig. 4, top shows myocyte cross-sectional area in sham ligation and HF groups. It was significantly larger in the HF vehicle group than in the 


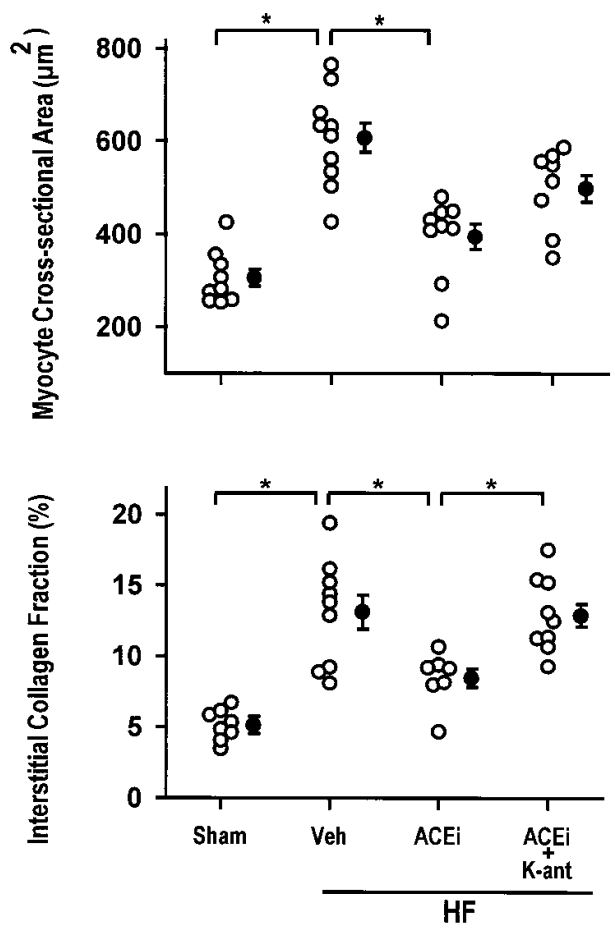

Figure 4. Effect of the angiotensin-converting enzyme inhibitor ramipril (ACEi) and ACEi plus the kinin antagonist icatibant (K-ant) on cardiomyocyte size (top) and interstitial collagen fraction (bottom) in sham-operated rats (Sham) and rats with chronic heart failure $(H F)$. $* P<0.05$. Veh, vehicle.

sham-ligated group $\left(607 \pm 31\right.$ vs $\left.306 \pm 18 \mu \mathrm{m}^{2} ; P<0.05\right)$. Ramipril significantly reduced myocyte size $\left(395 \pm 27 \mu \mathrm{m}^{2} ; P<\right.$ 0.05). Icatibant tended to reverse this effect $\left(499 \pm 29 \mu \mathrm{m}^{2}\right)$, but the difference was not statistically significant. The HF icatibant group $\left(570 \pm 26 \mu \mathrm{m}^{2}\right)$ was not significantly different from the $\mathrm{HF}$ vehicle group.

Interstitial collagen fraction. Fig. 4, bottom shows the volume fraction of interstitial collagen in sham-ligated and HF groups. It was significantly increased in the HF vehicle group compared with the sham-ligated group (13.1 $\pm 1.2 \%$ vs $5.1 \pm 0.4 \% ; P<0.05)$. Ramipril significantly reduced the col-
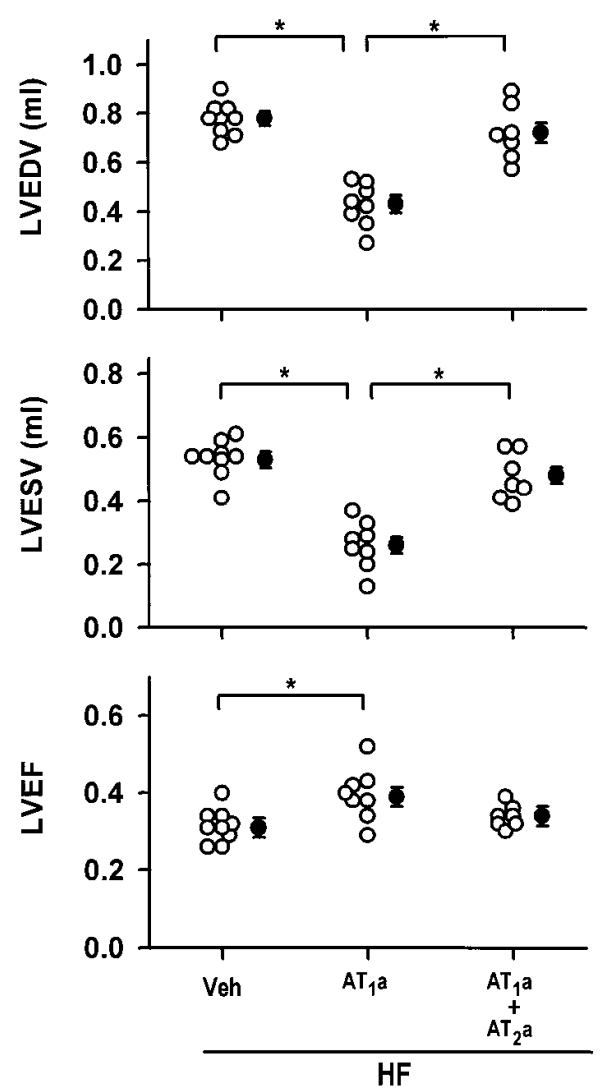

Figure 5. Effect of the $\mathrm{AT}_{1}$ antagonist $\mathrm{L} 158809\left(A T_{1} a\right)$ and $\mathrm{AT}_{1} \mathrm{a}+$ the $\mathrm{AT}_{2}$ antagonist PD123319 $\left(A T_{2} a\right)$ on left ventricular end-diastolic volume ( $L V E D V$, top), left ventricular end-systolic volume ( $L V E S V$, middle), and left ventricular ejection fraction $(L V E F$, bottom) in rats with chronic heart failure $(H F)$. ${ }^{*} P<0.05$. Veh, vehicle.

lagen fraction $(8.5 \pm 0.7 \% ; P<0.05)$, and icatibant reversed this effect $(12.9 \pm 0.8 \% ; P<0.05$ vs ramipril). The HF icatibant group $(12.5 \pm 0.6 \%)$ was not significantly different from HF vehicle.

Capillary density and oxygen diffusion distance. As shown in Table I, capillary density was significantly reduced in the HF vehicle group compared with sham ligation and was signifi-

Table II. Effect of $A T_{1}$-ant and $A T_{1}$-ant Plus either $A T_{2}$-ant or $B_{2}$ Kinin Antagonist (K-ant) on Body Weight, Hemodynamics, Ventricular Weight, Myocardial Infarct Size, Capillary Density, and Oxygen Diffusion Distance in Rats with Heart Failure

\begin{tabular}{|c|c|c|c|c|c|}
\hline & \multicolumn{5}{|c|}{ Heart failure } \\
\hline & Vehicle $(n=10)$ & $\mathrm{AT}_{1}$-ant $(n=8)$ & $\mathrm{AT}_{1}$-ant $+\mathrm{AT}_{2}$-ant $(n=7)$ & $\mathrm{AT}_{1}$-ant $+\mathrm{K}$-ant $(n=7)$ & $\mathrm{AT}_{2}$-ant $(n=7)$ \\
\hline BW (grams) & $532 \pm 6$ & $481 \pm 5.6^{*}$ & $448 \pm 5.4^{*}$ & $451 \pm 8.9 *$ & $478 \pm 13.5^{*}$ \\
\hline MBP (mmHg) & $116 \pm 3$ & $72 \pm 4 *$ & $66 \pm 5^{*}$ & $64 \pm 5^{*}$ & $109 \pm 4$ \\
\hline HR (beats/min) & $346 \pm 9$ & $342 \pm 9$ & $352 \pm 14$ & $353 \pm 7$ & $381 \pm 13$ \\
\hline LV/100 grams BW & $198 \pm 7$ & $168 \pm 3^{*}$ & $181 \pm 1$ & $160 \pm 2 *$ & $204 \pm 1$ \\
\hline RV/100 grams BW & $61 \pm 6$ & $50 \pm 2$ & $47 \pm 2$ & $52 \pm 1$ & $49 \pm 2$ \\
\hline IS ( $\%)$ & $37 \pm 1$ & $42 \pm 1$ & $37 \pm 2$ & $36 \pm 1$ & $41 \pm 1$ \\
\hline Capillary density $\left(\right.$ No. $\left./ \mathrm{mm}^{2}\right)$ & $905 \pm 46$ & $1346 \pm 81 *$ & $1183 \pm 46$ & $1075 \pm 70$ & $1082 \pm 52$ \\
\hline Oxygen diffusion distance $(\mu \mathrm{m})$ & $13.43 \pm 0.15$ & $11.31 \pm 0.18^{*}$ & $13.17 \pm 0.15^{\ddagger}$ & $10.5 \pm 0.11$ & $13.4 \pm 0.19$ \\
\hline
\end{tabular}

$\mathrm{BW}$, body weight; MBP, mean blood pressure; IS, infarct size. Each value represents the mean \pm SEM. $* P<0.05$ vs vehicle; ${ }^{*} P<0.05$ vs $\mathrm{AT}_{1}$-ant. Data for the sham and K-ant groups are shown in Table I. For the purpose of comparison, the data for the HF-vehicle group in Table I are shown again. 
cantly increased by ramipril. This effect was partially blocked by icatibant, though the difference was not significant compared with the ramipril group. Capillary density in the HF icatibant group was not significantly different from HF vehicle. Oxygen diffusion distance was significantly increased in the HF vehicle group compared with sham ligation and was significantly decreased by ramipril. This effect was partially blocked by icatibant, but the difference was not significant compared with the HF ramipril group. The HF icatibant group was not significantly different from $\mathrm{HF}$ vehicle.

Protocol II: role of $\mathrm{AT}_{2}$ receptors and kinins in the effect of $A T_{1}$-ant. Table II shows body weight, BP, HR, infarct size, and left and right ventricle weight for HF groups $\mathrm{f}-\mathrm{i}$. (The HF vehicle group is the same as in Table I and is included here for purposes of comparison.) $\mathrm{LV}$ weight was reduced in the $\mathrm{AT}_{1}$ ant and $\mathrm{AT}_{1}$-ant + icatibant groups compared with $\mathrm{HF}$ vehicle $(P<0.05)$. BP was significantly reduced in the $\mathrm{AT}_{1}$-ant group $(P<0.05)$, and this effect was not blocked by either $\mathrm{AT}_{2}$-ant or icatibant. LVEDP was $9.5 \pm 2.0 \mathrm{mmHg}$ in the vehicle-treated $\mathrm{HF}$ group and $2.0 \pm 0.9 \mathrm{mmHg}$ in the $\mathrm{AT}_{1}$ group $(P<0.05)$. LVEDP was not measured in the $\mathrm{AT}_{1}$-ant $+\mathrm{AT}_{2}$-ant, $\mathrm{AT}_{1}$ ant + icatibant, and $\mathrm{AT}_{2}$-ant groups due to technical difficulties with the equipment.

Ventricular volume and ejection fraction. Fig. 5 shows LVEDV, LVESV, and LVEF in HF rats treated with either vehicle, $\mathrm{AT}_{1}$-ant or $\mathrm{AT}_{1}$-ant $+\mathrm{AT}_{2}$-ant. In the $\mathrm{HF}$ vehicle group,
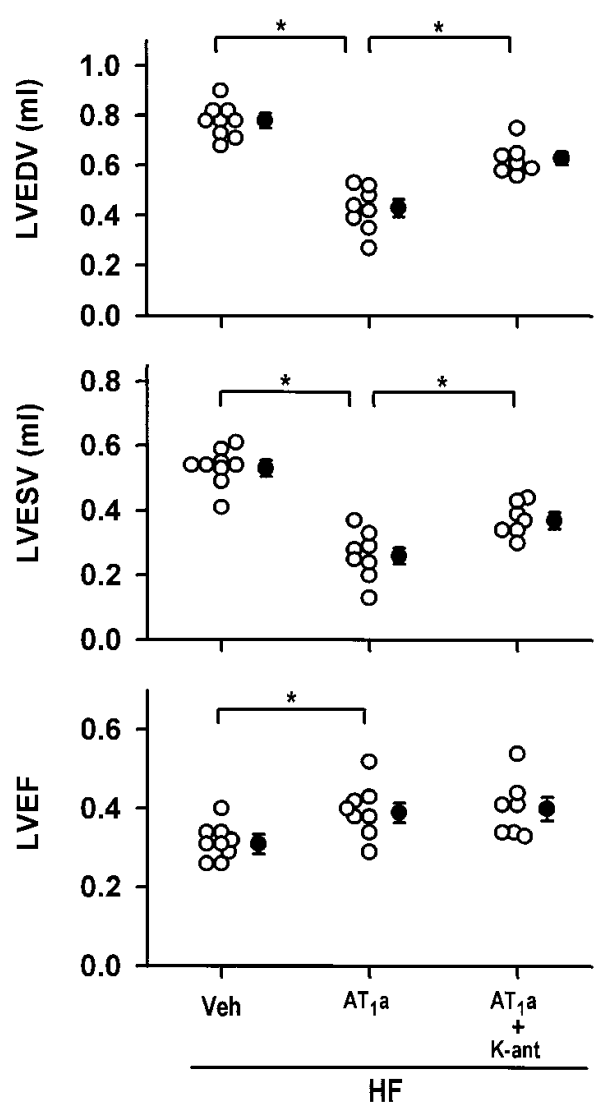

Figure 6. Effect of the $\mathrm{AT}_{1}$ antagonist $\mathrm{L} 158809\left(A T_{1} a\right)$ and $\mathrm{AT}_{1} \mathrm{a}+$ the kinin antagonist icatibant $(K$-ant) on left ventricular end-diastolic volume ( $L V E D V$, top), left ventricular end-systolic volume ( $L V E S V$, middle), and left ventricular ejection fraction ( $L V E F$, bottom) in rats with chronic heart failure $(H F) . * P<0.05$. Veh, vehicle.
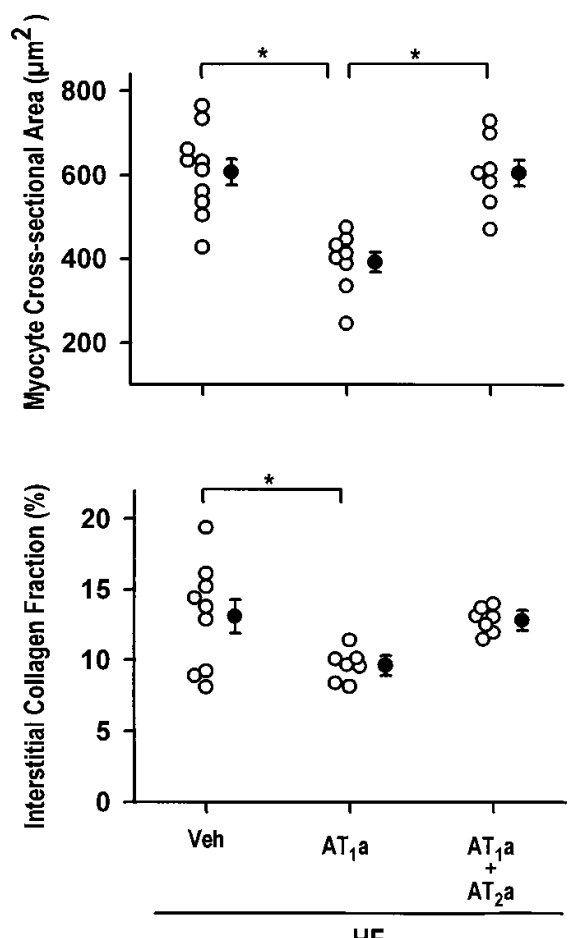

HF

Figure 7. Effect of the $\mathrm{AT}_{1}$ antagonist $\mathrm{L} 158809\left(A T_{1} a\right)$ or $\mathrm{AT}_{1}$ a plus the $\mathrm{AT}_{2}$ antagonist PD123319 $\left(A T_{2} a\right)$ on cardiomyocyte size (top) and interstitial collagen fraction (bottom) in rats with chronic heart failure $(H F) . * P<0.05$. Veh, vehicle.

LVEDV was $0.78 \pm 0.02 \mathrm{ml}$ and LVESV was $0.53 \pm 0.02 \mathrm{ml}$. In the $\mathrm{AT}_{1}$-ant group, LVEDV was $0.43 \pm 0.03 \mathrm{ml}$ and LVESV was $0.26 \pm 0.02 \mathrm{ml}(P<0.05$ vs vehicle $)$. The effect of $\mathrm{AT}_{1}$-ant on LVEDV and LVESV was blocked by $\mathrm{AT}_{2}$-ant $(0.72 \pm 0.04$ and $0.48 \pm 0.03 \mathrm{ml} ; P<0.05$ vs $\mathrm{AT}_{1}$-ant). Fig. 6 shows the effect of icatibant. $\mathrm{B}_{2}$-ant partially blocked the effect of $\mathrm{AT}_{1}$-ant on LVEDV and LVESV $(0.63 \pm 0.02$ and $0.37 \pm 0.02 \mathrm{ml} ; P<0.05$ vs $\mathrm{AT}_{1}$-ant) but not the effect on LVEF.

$\mathrm{AT}_{1}$-ant increased LVEF (0.4 \pm 0.02$)$ compared with $\mathrm{HF}$ vehicle $(0.31 \pm 0.01 ; P<0.05)$, and this effect was not prevented by either $\mathrm{AT}_{2}$-ant (Fig. 4) or icatibant (Fig. 5). In the HF group treated with $\mathrm{AT}_{2}$-ant alone, LVEDV, LVESV, or LVEF was no different than the HF vehicle group (Fig. 2).

Cardiomyocyte hypertrophy (Fig. 7, top). $\mathrm{AT}_{1}$-ant significantly reduced myocyte cross-sectional area compared with the HF vehicle group $\left(392 \pm 24\right.$ vs $\left.607 \pm 31 \mu \mathrm{m}^{2} ; P<0.05\right)$, and this effect was blocked by $\mathrm{AT}_{2}$-ant $\left(605 \pm 31 \mu \mathrm{m}^{2} ; P<0.05\right.$ vs $\mathrm{AT}_{1}$-ant). $\mathrm{AT}_{2}$-ant alone did not increase myocyte cross-sectional area further $\left(618 \pm 35 \mu \mathrm{m}^{2}\right)$. It was larger in the $\mathrm{AT}_{1}$ ant + icatibant group $\left(425 \pm 25 \mu \mathrm{m}^{2}\right)$ than in the $\mathrm{AT}_{1}$-ant group, but the difference was not statistically significant.

Interstitial fibrosis (Fig. 7, bottom). Interstitial collagen fraction was $13.1 \pm 1.2 \%$ in the HF vehicle group and $9.6 \pm 0.4 \%$ in the $\mathrm{AT}_{1}$-ant group $(P<0.05)$. The $\mathrm{AT}_{2}$-ant blocked this effect $(12.8 \pm 0.3 \%)$, but the blockade was not statistically significant. The $\mathrm{B}_{2}$-ant icatibant $(9.42 \pm 0.78 \%)$ did not alter the effect of the $\mathrm{AT}_{1}$-ant.

Capillary density and oxygen diffusion distance (Table II). $\mathrm{AT}_{1}$-ant increased capillary density significantly and this effect was blocked by $\mathrm{AT}_{2}$-ant or icatibant, but the differences did 
not reach statistical significance. $\mathrm{AT}_{1}$-ant decreased oxygen diffusion distance compared to the HF vehicle group; this effect was blocked by $\mathrm{AT}_{2}$-ant but not icatibant.

\section{Discussion}

As expected, our study showed that chronic treatment with an ACEi improves LV function and attenuates remodeling (LVEDV and LVESV) in rats with chronic HF due to MI. Some of the changes caused by the ACEi were small, as for example the increase in LVEF; however, this increase occurred simultaneously with decreases in LVEDP, suggesting that the pumping ability of the LV was significantly improved. Cardiomyocyte cross-sectional area (an indicator of myocyte volume), interstitial collagen fraction, and oxygen diffusion distance were all decreased by the ACEi whereas capillary density was increased, indicating that LV remodeling at the cellular level may have been attenuated as well. We observed that many but not all effects of the ACEi were blocked by the kinin $\mathrm{B}_{2}$-ant icatibant, supporting the hypothesis that inhibition of kinin hydrolysis contributes to the therapeutic effect of the ACEi in chronic HF. Treatment with the $\mathrm{B}_{2}$-ant by itself did not have any effect on function and remodeling compared with the HF vehicle group, suggesting either that in the absence of ACEi, kinins are present at concentrations that do not affect the progression of HF, or else blockade of the reninangiotensin system (RAS) is necessary for kinins to have a cardioprotective effect, or both. We observed similar effects when the rats were treated with the $\mathrm{AT}_{1}$-ant. Most but not all effects of the $\mathrm{AT}_{1}$-ant were blocked by PD123319, which is known to be a specific blocker of the $\mathrm{AT}_{2}$ receptor (31), thus supporting the hypothesis that the effect of the $\mathrm{AT}_{1}$-ant is mediated in part by activation of the $\mathrm{AT}_{2}$ receptor. The $\mathrm{AT}_{2}$-ant by itself did not have any effect on LV function or remodeling compared to the $\mathrm{HF}$ vehicle group, suggesting that the $\mathrm{AT}_{2}$ receptor may exert a cardioprotective effect only when the $\mathrm{AT}_{1}$ receptor is blocked. Also, the effect of the $\mathrm{AT}_{1}$-ant on LVEDV and LVESV was partially blocked by the $\mathrm{B}_{2}$-ant whereas other effects were not. The fact that $\mathrm{B}_{2}$-ant blocked the effect of both ACEi and $\mathrm{AT}_{1}$-ant on LVEDV and LVESV but not on LVEF may be interpreted as an indication that the ACEi and $\mathrm{AT}_{1}$-ant may have an effect on the contractile state, which is more related to inhibition of angiotensin II rather than potentiation of kinins. Actually, $\mathrm{ACEi}$ and $\mathrm{AT}_{1}$-ant decreased LVESV by 47.2 and $51 \%$ while LVEDV decreased by only 39.7 and $44.9 \%$, respectively. The greater decrease in systolic volume may reflect an effect of $\mathrm{ACEi}$ and $\mathrm{AT}_{1}$-ant on cardiac contractility. Taken together, these results support the hypothesis that in HF the chronic therapeutic effect of ACEi is due to not only blockade of the conversion of Ang I to Ang II but also inhibition of kinin hydrolysis, while that of the $\mathrm{AT}_{1}$-ant is due to not only blockade of the $\mathrm{AT}_{1}$ receptor but also activation of the $\mathrm{AT}_{2}$ receptor, which has a therapeutic effect in $\mathrm{HF}$ either directly or via the release of kinins and/or other autacoids as illustrated by Fig. 8 .

The mechanism by which activation of the kinin $B_{2}$ receptor may produce cardioprotection is not well established. Farhy et al. (13) in our laboratory have shown that ACEi reduce neointima formation after carotid injury and that this effect is mediated by kinins, eicosanoids and NO. Their study suggests that ACEi acting via kinins-eicosanoids-NO have an antitrophic effect. Our study further supports the hypothesis that ACEi acting via kinins have an antitrophic effect in chronic $\mathrm{HF}$, since ventricular volume, myocyte size, and interstitial fibrosis were decreased by the ACEi and these effects were partially blocked by the $\mathrm{B}_{2}$-ant (Figs. 1 and 4). Although blockade of the effect of ACEi on myocyte size, capillary density, and oxygen diffusion distance by the $\mathrm{B}_{2}$-ant did not reach statistical significance, it tended to change in the anticipated direction. It could be that the effects of ACEi on these parameters are mainly due to a decrease in Ang II concentrations, and that increased tissue kinins play primarily a modulatory role.

There is mounting evidence that kinins participate in the cardioprotective effect of ACEi. Linz et al. (32) reported that kinins mediate the cardiac antihypertrophic and antihypertensive effect of ACEi in rats with aortic coarctation. They also indicated that kinins mediate the cardiac antihypertrophic effect of ACEi when used at doses that do not have an antihy-

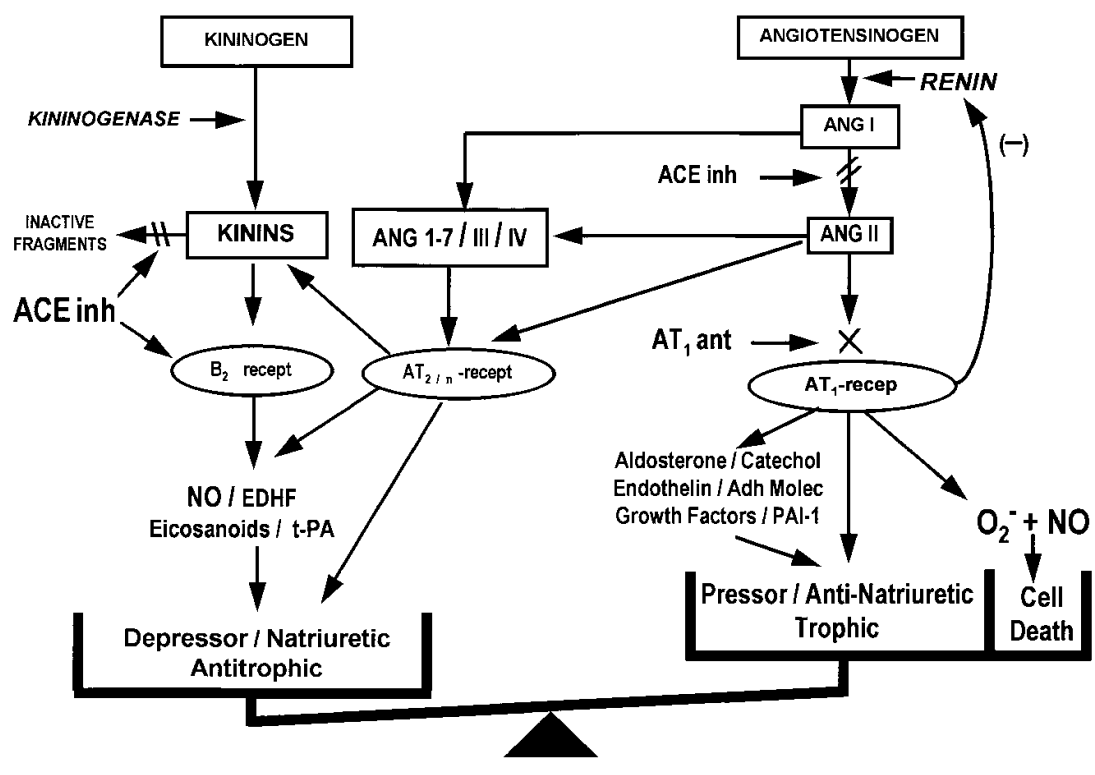

Figure 8. Hypothesis on the mechanism of action of ACEi and $\mathrm{AT}_{1}$-ant in HF. ACEi act by blocking both conversion of Ang I to Ang II and hydrolysis of kinins. Acting via the $\mathrm{B}_{2}$ receptor, kinins stimulate the release of various autacoids such as NO, endothelium-derived hyperpolarizing factor $(E D H F)$, eicosanoids and tissue plasminogen activator $(t-P A)$. $\mathrm{AT}_{1}$-ant block the corresponding receptor, causing increased renin release which results in the formation of angiotensins. These angiotensins act on the $\mathrm{AT}_{2}$ receptor, which induces the release of autacoids similar to those stimulated by kinins. 
pertensive effect; however, we have been unable to confirm this study (33). Gohlke et al. (34) have demonstrated that kinins mediate the chronic cardioprotective effect of ACEi in stroke-prone spontaneously hypertensive rats when administered starting early in life. More recently, McDonald et al. (35, 36) found that treatment with an ACEi starting immediately after induction of myocardial necrosis prevented an early increase in $\mathrm{LV}$ mass while treatment with an $\mathrm{AT}_{1}$-ant did not. The effect of the ACEi was abolished by icatibant, suggesting that kinins are important during the early remodeling phase. There is also evidence that the cardioprotective effect of ACEi during ischemia/reperfusion is mediated by kinins, not blockade of Ang II formation (12,14). Furthermore, in this situation the effect of kinins appears to be mediated by prostaglandins and NO (12). Thus overall the above mentioned work suggests that part of the cardiovascular effect of ACEi is mediated by kinins, perhaps via the release of prostaglandins and NO. However, the role of kinins in the effect of ACEi in HF is not well established. Stauss et al. (37) reported that in rats, administration of ACEi before coronary ligation resulted in reduced infarct size, heart weight, and end-diastolic pressure. All of these effects were blocked by concomitant administration of icatibant. However, from their study it is not possible to determine whether ACEi acting via kinins prevented remodeling and HF after MI, since the ACEi was administered before induction of infarction so that the infarcted area was smaller than in the untreated rats; and studies have shown that development of HF is directly related to MI size (38).

Two major Ang II receptor subtypes have been identified, $\mathrm{AT}_{1}$ and $\mathrm{AT}_{2}$ (19). Of the total Ang II receptors found in the normal rat ventricle, $\sim 31 \%$ are $\mathrm{AT}_{2}$, while during $\mathrm{LVH} \mathrm{AT}_{2}$ increases to $\sim 60 \%$ (39). In our study the $\mathrm{AT}_{1}$-ant exhibited a cardioprotective effect similar to ACEi. Combined use of $\mathrm{AT}_{1}$ ant and $\mathrm{AT}_{2}$-ant blocked most of the beneficial effect of the $\mathrm{AT}_{1}$-ant. However, the mechanism by which activation of the $\mathrm{AT}_{2}$ receptor may produce cardioprotection is not known. Most known effects of Ang II, such as increasing BP, stimulating myocyte hypertrophy and increasing collagen synthesis, are attributed to the $\mathrm{AT}_{1}$ receptor $(40,41)$ whereas $\mathrm{AT}_{2}$ receptors, which are primarily embryonic, may be activated during development of cardiac hypertrophy and HF (39, 41-43). There is evidence that the $\mathrm{AT}_{2}$ receptor antagonizes both pressor and growth effects of the $\mathrm{AT}_{1}$ receptor $(21,44)$; however, neither the mediator nor the second messenger of this receptor is well established. It could be that the $\mathrm{AT}_{2}$ receptor exerts its beneficial effects on HF by stimulating local release of $\mathrm{NO}$ either directly or via kinins $(23,24,45)$, which together with blockade of the $\mathrm{AT}_{1}$ receptor may have an antitrophic effect; consequently, LV remodeling regresses and LV function improves. It has been reported that in cultured bovine aortic endothelial cells, Ang II induced a six- to sevenfold increase in the release of cGMP; this effect was abolished by a kinin antagonist and a NO synthesis inhibitor and markedly inhibited by an $\mathrm{AT}_{2}$-ant, but only marginally inhibited by an $\mathrm{AT}_{1}$-ant (46), suggesting that Ang II-stimulated release of NO is predominantly due to stimulation of the $\mathrm{AT}_{2}$ receptor and may lead to an increase in the effect of kinins, stimulation of NO and increased cGMP formation. Also, in isolated microvessels of the dog heart, it has been shown that angiotensins stimulate cGMP via either the $\mathrm{AT}_{2}$ and/or a non- $\mathrm{AT}_{1}$ or $\mathrm{AT}_{2}$ receptor $\left(\mathrm{AT}_{\mathrm{n}}\right)$, kinins, and NO (46). Brosnihan et al. (47) recently reported that Ang 1-7 dilates canine coronary arteries through kinins and NO via $\mathrm{AT}_{\mathrm{n}}$. Also, Siragy and Carey (23) recently reported that during low sodium intake angiotensins stimulate increased renal interstitial cGMP via the $\mathrm{AT}_{2}$ receptor. Thus it is possible that during blockade of the $\mathrm{AT}_{1}$ receptor, activation of the $\mathrm{AT}_{2}$ or $\mathrm{AT}_{\mathrm{n}}$ receptor may mediate some of the cardiovascular effects of $\mathrm{AT}_{1}$-ant either directly or via kinins and/or $\mathrm{NO}$ and cGMP. We also tested whether the effects of the $\mathrm{AT}_{1^{-}}$ ant are mediated by kinins and found that the kinin $\mathrm{B}_{2}$-ant partially blocked the effects of the $\mathrm{AT}_{1}$-ant on LVEDV and LVESV, but not its other effects. We interpreted these data as suggesting that during blockade of the $\mathrm{AT}_{1}$ receptor, kinin levels normally present in tissue exert an effect that leads to reduction of ventricular volume. Another possible explanation could be that during $\mathrm{AT}_{1}$ blockade, activation of $\mathrm{AT}_{2}$ receptors may lead to an increase in either tissue kinin concentrations or the effect of kinins (47).

$\mathrm{ACEi}$ and $\mathrm{AT}_{1}$-ant may exert a cardioprotective effect by causing hemodynamic changes and/or by a direct effect on the heart. In our study, both $\mathrm{ACEi}$ and $\mathrm{AT}_{1}$-ant decreased $\mathrm{BP}$ and this hypotensive effect was not blocked by either $\mathrm{B}_{2}$-ant or $\mathrm{AT}_{2}$-ant. We interpreted these data as indicating that a decrease in afterload was not the main cause of the cardioprotective effect. However, we cannot exclude an effect on preload, especially since both $\mathrm{ACEi}$ and $\mathrm{AT}_{1}$-ant may result in natriuresis and diuresis (acting via blockade of the renin-angiotensin system, an increase in tissue kinins and/or activation of the $\mathrm{AT}_{2}$ receptor) (48-50). In addition, by increasing $\mathrm{NO}$ they may cause venous dilation. All of these actions may lead to a decrease in preload and LV chamber radius and consequently decrease end-diastolic stress (51-53). Since LVEDP was decreased by both $\mathrm{ACEi}$ and $\mathrm{AT}_{1}$-ant, it could be that decreased preload is important for the therapeutic effects we observed (51). Also, the $\mathrm{B}_{2}$-ant blocked the effect of the $\mathrm{AT}_{1}$-ant on $\mathrm{LV}$ volume but not its effect on cardiocyte hypertrophy or collagen deposition, suggesting that some of the effects we observed may be due to a decrease in preload secondary to diuresis and/or venous dilation caused by kinins. It has been shown that diuretics decrease LV mass mainly by reducing chamber diameter; however, they failed to decrease LV wall thickness and prevent remodeling $(51,53)$. This could be due to the fact that diuretics stimulate the renin-angiotensin system; the potent vasoconstrictor and myocardial growth-promoting action of Ang II may offset the cardiac benefit of diuretics.

On the other hand, we and others have shown that components of the kallikrein-kinin system are found in the heart (11, $54,55)$, while kinins are found in the effluent of isolated perfused hearts and are increased by ACEi as well as by ischemia $(56,57)$. Furthermore, ACEi significantly increase kinin concentrations in the heart and vascular tissue (58). Receptors for kinins have also been localized to cardiac tissue (59). Moreover, the heart also has a renin-angiotensin system $(60,61)$, and isolated cardiocytes respond to stretching by forming Ang II (62), which in turn acts as a growth factor $(63,64)$, though there is some controversy regarding the existence of intrinsic cardiac renin (65). Recently it was reported that after MI the number of angiotensin $\mathrm{AT}_{2}$ receptors in the heart increases (42). Thus the components of both renin-angiotensin and kallikrein-kinin systems are present in the heart, making it feasible that some of the effects we observed are local. Furthermore, decreasing afterload does not necessarily result in cardiac remodeling in HF. Cohn showed that in patients with chronic HF, the vasodilator prazosin failed to exert an antire- 
modeling effect (66). Similar results were obtained by McDonald et al. (36) in a canine model of remodeling, in which the $\alpha$-blocker terazosin failed to inhibit remodeling whereas ACEi and nitrates did. Additionally, in the CONSENSUS study (2) the decreased mortality which occurred during treatment with ACEi was also observed in patients treated with vasodilators (nitrates and hydralazine), suggesting that the benefit of ACEi goes beyond hemodynamic effects. Taken together, these data may suggest that the beneficial cardiac effects of $\mathrm{ACEi}$ and $\mathrm{AT}_{1}$-ant are not only dependent on their hemodynamic action, but also probably interfere with autocrine/ paracrine actions involving the cardiac renin-angiotensin and kallikrein-kinin systems $(10,11)$. Nevertheless, based on our study it is not possible to determine whether the effects of $\mathrm{ACEi}$ and $\mathrm{AT}_{1}$-ant on cardiac function and remodeling are due to changes in autacoids acting either directly on the heart or secondary to hemodynamic effects or (more probably) both.

In conclusion, in Lewis inbred rats with chronic HF due to MI, both $\mathrm{ACEi}$ and $\mathrm{AT}_{1}$-ant have a cardioprotective effect, manifested by attenuation of LV chamber remodeling. The effects of the ACEi are mediated in part by kinins, while those of the $\mathrm{AT}_{1}$-ant are triggered by activation of the $\mathrm{AT}_{2}$ receptor. The decrease in ventricular volume caused by the $\mathrm{AT}_{1}$-ant is also mediated in part by kinins. We speculate that in $\mathrm{HF}$, blockade of $\mathrm{AT}_{1}$ receptors increases both renin and angiotensins; these angiotensins stimulate the $\mathrm{AT}_{2}$ receptor, which in turn may play an important role in the therapeutic effect of the $\mathrm{AT}_{1}$-ant via kinins and other autacoids. Thus the mechanisms by which $\mathrm{ACEi}$ and $\mathrm{AT}_{1}$-ant work in $\mathrm{HF}$ are similar, in that both block the renin-angiotensin system and both may induce the release of similar autacoids.

\section{Acknowledgments}

This work was supported by National Institutes of Health grant HL28982, grant 31GS956 from the American Heart Association of Michigan (X.-P. Yang), a grant from Henry Ford Hospital (Y.-H. Liu) and a grant from the Fujimoto Corporation (O.A. Carretero).

\section{References}

1. Gavras, H., D.P. Faxon, J. Berkoben, H.R. Brunner, and T.J. Ryan. 1978. Angiotensin converting enzyme inhibition in patients with congestive heart failure. Circulation. 58:770-776.

2. The CONSENSUS Trial Study Group. 1987. Effects of enalapril on mortality in severe congestive heart failure. Results of the Cooperative North Scandinavian Enalapril Survival Study (CONSENSUS). N. Engl. J. Med. 316:14291435 .

3. Pfeffer, M.A., E. Braunwald, L.A. Moyé, L. Basta, E.J. Brown, Jr., T.E. Cuddy, B.R. Davis, E.M. Geltman, S. Goldman, G.C. Flaker, et al. 1992. Effect of captopril on mortality and morbidity in patients with left ventricular dysfunction after myocardial infarction. Results of the survival and ventricular enlargement trial. N. Engl. J. Med. 327:669-677.

4. The SOLVD Investigators. 1992. Effect of enalapril on mortality and the development of heart failure in asymptomatic patients with reduced left ventricular ejection fractions. N. Engl. J. Med. 327:685-691.

5. Acute Infarction Ramipril Efficacy (AIRE) study investigators. 1993. Effect of ramipril on mortality and morbidity of survivors of acute myocardial infarction with clinical evidence of heart failure. Lancet. 342:821-828.

6. Gavras, H., and I. Gavras. 1991. Cardioprotective potential of angiotensin converting enzyme inhibitors. J. Hypertens. 9:385-392.

7. Garg, R., and S. Yusuf, for the Collaborative Group on ACE Inhibitor Trials. 1995. Overview of randomized trials of angiotensin-converting enzyme inhibitors on mortality and morbidity in patients with heart failure [review]. $J$. Am. Med. Assoc. 273:1450-1456.

8. Carretero, O.A., and A.G. Scicli. 1995. The kallikrein-kinin system as a regulator of cardiovascular and renal function. In Hypertension: Physiology,
Diagnosis, and Management. J.H. Laragh and B.M. Brenner, editors. Raven Press, New York. 983-999.

9. Gavras, I., A. Manolis, and H. Gavras. 1995. Effects of ACE inhibition on the heart. J. Hum. Hypertens. 9:455-458.

10. Carretero, O.A., A.G. Scicli, and S.R. Maitra. 1981. Role of kinins in the pharmacological effects of converting enzyme inhibitors. In Angiotensin Converting Enzyme Inhibitors. Mechanisms of Action and Clinical Implications. Z.P. Horovitz, editor. Urban \& Schwarzenberg, Baltimore. 105-121.

11. Linz, W., and B.A. Schölkens. 1992. Role of bradykinin in the cardiac effects of angiotensin-converting enzyme inhibitors. J. Cardiovasc. Pharmacol. 20 (Suppl. 9):S83-S90.

12. Liu, Y.-H., X.-P. Yang, V.G. Sharov, D.H. Sigmon, H.N. Sabbah, and O.A. Carretero. 1996. Paracrine systems in the cardioprotective effect of angiotensin-converting enzyme inhibitors on myocardial ischemia/reperfusion injury in rats. Hypertension (Dallas). 27:7-13.

13. Farhy, R.D., O.A. Carretero, K.-L. Ho, and A.G. Scicli. 1993. Role of kinins and nitric oxide in the effects of angiotensin converting enzyme inhibitors on neointima formation. Circ. Res. 72:1202-1210.

14. Hartman, J.C., T.M. Wall, T.G. Hullinger, and R.J. Shebuski. 1993. Reduction of myocardial infarct size in rabbits by ramiprilat: reversal by the bradykinin antagonist HOE 140. J. Cardiovasc. Pharmacol. 21:996-1003.

15. Abassi, Z.A., G. Kelly, E. Golomb, H. Klein, and H.R. Keiser. 1994. Losartan improves the natriuretic response to ANF in rats with high-output heart failure. J. Pharmacol. Exp. Ther. 268:224-230.

16. Dickstein, K., P. Chang, R. Willenheimer, S. Haunso, J. Remes, C. Hall, and J. Kjekshus. 1995. Comparison of the effects of losartan and enalapril on clinical status and exercise performance in patients with moderate or severe chronic heart failure. J. Am. Coll. Cardiol. 26:438-445.

17. Dickstein, K., S. Gottlieb, E. Fleck, J. Kostis, B. Levine, M. DeKock, and T. LeJemtel. 1994. Hemodynamic and neurohumoral effects of the angiotensin II antagonist losartan in patients with heart failure. J. Hypertens. (Suppl.) 12:S31-S35

18. Gottlieb, S.S., K. Dickstein, E. Fleck, J. Kostis, T.B. Levine, T. LeJemtel, and M. DeKock. 1993. Hemodynamic and neurohormonal effects of the angiotensin II antagonist losartan in patients with congestive heart failure. Circulation. 88:1602-1609.

19. Whitebread, S., M. Mele, B. Kamber, and M. de Gasparo. 1989. Preliminary biochemical characterization of two angiotensin II receptor subtypes. Biochem. Biophys. Res. Commun. 163:284-291.

20. Campbell, D.J., A. Kladis, and A.J. Valentijn. 1995. Effects of losartan on angiotensin and bradykinin peptides and angiotensin-converting enzyme. $J$. Cardiovasc. Pharmacol. 26:233-240.

21. Nakajima, M., H.G. Hutchinson, M. Fujinaga, W. Hayashida, R. Morishita, L. Zhang, M. Horiuchi, R.E. Pratt, and V.J. Dzau. 1995. The angiotensin II type $2\left(\mathrm{AT}_{2}\right)$ receptor antagonizes the growth effects of the $\mathrm{AT}_{1}$ receptor: gain-of-function study using gene transfer. Proc. Natl. Acad. Sci. USA. 92: 10663-10667.

22. Stoll, M., U.M. Steckelings, M. Paul, S.P. Bottari, R. Metzger, and T. Unger. 1995. The angiotensin $\mathrm{AT}_{2}$-receptor mediates inhibition of cell proliferation in coronary endothelial cells. J. Clin. Invest. 95:651-657.

23. Siragy, H.M., and R.M. Carey. 1996. The subtype-2 $\left(\mathrm{AT}_{2}\right)$ angiotensin receptor regulates renal cyclic guanosine $3^{\prime}, 5^{\prime}$-monophosphate and $\mathrm{AT}_{1}$ receptor-mediated prostaglandin $\mathrm{E}_{2}$ production in conscious rats. J. Clin. Invest. 97: 1978-1982.

24. Seyedi, N., X. Xu, A. Nasjletti, and T.H. Hintze. 1995. Coronary kinin generation mediates nitric oxide release after angiotensin receptor stimulation. Hypertension (Dallas). 26:164-170.

25. Liu, Y.-H., X.-P. Yang, O. Nass, H.N. Sabbah, E. Peterson, and O.A. Carretero. 1997. Chronic heart failure induced by coronary artery ligation in Lewis inbred rats. Am. J. Physiol. 272:H722-H727.

26. Yang, X.-P., H.N. Sabbah, Y.-H. Liu, V.G. Sharov, E.J. Mascha, I. Alwan, and O.A. Carretero. 1993. Ventriculographic evaluation in three rat models of cardiac dysfunction. Am. J. Physiol. 266:H1946-H1952.

27. Yang, S.S., L.G. Bentivoglio, V. Maranhao, and H. Goldberg. 1978. Cardiac volume. In From Cardiac Catheterization Data to Hemodynamic Parameters. S.S. Yang, editor. F.A. Davis, Philadelphia. 101-151.

28. Hansen-Smith, F.M., L. Watson, D.Y. Lu, and I. Goldstein. 1988. Griffonia simplicifolia I: fluorescent tracer for microcirculatory vessels in nonperfused thin muscles and sectioned muscle. Microvasc. Res. 36:199-215.

29. Laitinen, L. 1987. Griffonia simplicifolia lectins bind specifically to endothelial cells and some epithelial cells in mouse tissues. Histochem. J. 19:225234

30. Rakušan, K. 1971. Changes in the myocardial oxygen tension caused by changes in several oxygen determinants, with special consideration of the diffusion distance. In Oxygen in the Heart Muscle. Charles C. Thomas Publisher, Springfield, Ill. 66-71.

31. Carini, D.J., J.V. Duncia, P.E. Aldrich, A.T. Chiu, A.L. Johnson, M.E. Pierce, W.A. Price, J.B. Santella III, G.J. Wells, R.R. Wexler, et al. 1991. Nonpeptide angiotensin II receptor antagonists: the discovery of a series of $N$-(biphenylylmethyl) imidazoles as potent, orally active antihypertensives. J. Med. Chem. 34:2525-2547.

32. Linz, W., G. Wiemer, and B.A. Schölkens. 1993. Bradykinin prevents 
left ventricular hypertrophy in rats. J. Hypertens. 11 (Suppl. 5):S96-S97.

33. Rhaleb, N.-E., X.-P. Yang, A.G. Scicli, and O.A. Carretero. 1994. Role of kinins and nitric oxide in the antihypertrophic effect of ramipril. Hypertension (Dallas). 23:865-868.

34. Gohlke, P., W. Linz, B.A. Schölkens, I. Kuwer, S. Bartenbach, A. Schnell, and T. Unger. 1994. Angiotensin converting enzyme inhibition improves cardiac function. Role of bradykinin. Hypertension (Dallas). 23:411-418.

35. McDonald, K.M., J. Mock, A. D'Aloia, T. Parrish, K. Hauer, G. Francis, A. Stillman, and J.N. Cohn. 1995. Bradykinin antagonism inhibits the antigrowth effect of converting enzyme inhibition in the dog myocardium after discrete transmural myocardial necrosis. Circulation. 91:2043-2048.

36. McDonald, K.M. M. Garr, P.F. Carlyle, G.S. Francis, K. Hauer, D.W. Hunter, T. Parish, A. Stillman, and J.N. Cohn. 1994. Relative effects of $\alpha 1$ adrenoceptor blockade, converting enzyme inhibitor therapy, and angiotensin II subtype 1 receptor blockade on ventricular remodeling in the dog. Circulation. 90:3034-3046.

37. Stauss, H.M., Y.-C. Zhu, T. Redlich, D. Adamiak, A. Mott, K.C. Kregel, and T. Unger. 1994. Angiotensin-converting enzyme inhibition in infarct-induced heart failure in rats: bradykinin versus angiotensin II. J. Cardiovasc. Risk. 1: 255-262.

38. Fletcher, P.J., J.M. Pfeffer, M.A. Pfeffer, and E. Braunwald. 1981. Left ventricular diastolic pressure-volume relations in rats with healed myocardial infarction. Effects on systolic function. Circ. Res. 49:618-626.

39. Lopez, J.J., B.H. Lorell, J.R. Ingelfinger, E.O. Weinberg, H. Schunkert, D. Diamant, and S.-S. Tang. 1994. Distribution and function of cardiac angiotensin $\mathrm{AT}_{1}$ - and $\mathrm{AT}_{2}$-receptor subtypes in hypertrophied rat hearts. Am. J. Physiol. 267:H844-H852.

40. Ganz, M.B., M.C. Perfetto, and W.F. Boron. 1990. Effects of mitogens and other agents on rat mesangial cell proliferation, $\mathrm{pH}$, and $\mathrm{Ca}^{2+}$. Am. J. Physiol. 259:F269-F278.

41. Everett, A.D., A. Tufro-McReddie, A. Fisher, and R.A. Gomez. 1994 Angiotensin receptor regulates cardiac hypertrophy and transforming growth factor- $\beta 1$ expression. Hypertension (Dallas). 23:587-592.

42. Nio, Y., H. Matsubara, S. Murasawa, M. Kanasaki, and M. Inada. 1995. Regulation of gene transcription of angiotensin II receptor subtypes in myocardial infarction. J. Clin. Invest. 95:46-54.

43. Suzuki, J., H. Matsubara, M. Urakami, and M. Inada. 1993. Rat angiotensin II (type 1A) receptor mRNA regulation and subtype expression in myocardial growth and hypertrophy. Circ. Res. 73:439-447.

44. Ichiki, T., P.A. Labosky, C. Shiota, S. Okuyama, Y. Imagawa, A. Fogo, F. Niimura, I. Ichikawa, B.L. Hogan, and T. Inagami. 1995. Effects on blood pressure and exploratory behaviour of mice lacking angiotensin II type-2 receptor. Nature (Lond.). 377:748-750.

45. Hecker, M., I. Porsti, and R. Busse. 1994. Mechanisms involved in the angiotensin II-independent hypotensive action of ACE inhibitors. Braz. J. Med. Biol. Res. 27:1917-1921.

46. Seyedi, N., X. Xu, A. Nasjletti, and T.H. Hintze. 1995. Coronary kinin generation mediates nitric oxide release after angiotensin receptor stimulation. Hypertension (Dallas). 26:164-170.

47. Brosnihan, K.B., P. Li, and C.M. Ferrario. 1996. Angiotensin-(1-7) dilates canine coronary arteries through kinins and nitric oxide. Hypertension (Dallas). 27:523-528.

48. Tomiyama, H., A.G. Scicli, G.M. Scicli, and O.A. Carretero. 1990. Renal effects of Fab fragments of kinin antibodies on deoxycorticosterone acetate- salt-treated rats. Hypertension (Dallas). 15:761-766.

49. Saitoh, S., A.G. Scicli, E. Peterson, and O.A. Carretero. 1995. Effect of inhibiting renal kallikrein on prostaglandin $\mathrm{E}_{2}$, water, and sodium excretion. Hypertension (Dallas). 25:1008-1013.

50. Lo, M., K.-L. Liu, P. Lantelme, and J. Sassard. 1995. Subtype 2 of angiotensin II receptors controls pressure-natriuresis in rats. J. Clin. Invest. 95:13941397

51. Dahlöf, B. 1992. Regression of left ventricular hypertrophy-are there differences between antihypertensive agents? Cardiology. 81:307-315.

52. Liebson, P.R., G.A. Grandits, S. Dianzumba, R.J. Prineas, R.H. Grimm, Jr., J.D. Neaton, and J. Stamler, for the Treatment of Hypertension Study Research Group. 1995. Comparison of five antihypertensive monotherapies and placebo for change in left ventricular mass in patients receiving nutritionalhygienic therapy in the Treatment of Mild Hypertension Study (TOMHS). Circulation. 91:698-706.

53. Sharpe, N., J. Murphy, H. Smith, and S. Hannan. 1990. Preventive treatment of asymptomatic left ventricular dysfunction following myocardial infarction. Eur. Heart J. 11 (Suppl. B):147-156.

54. Nolly, H., L.A. Carbini, G. Scicli, O.A. Carretero, and A.G. Scicli. 1994 A local kallikrein-kinin system is present in rat hearts. Hypertension (Dallas). 23:919-923.

55. Nolly, H., O.A. Carretero, and A.G. Scicli. 1993. Kallikrein release by vascular tissue. Am. J. Physiol. 265:H1209-H1214.

56. van Gilst, W.H., R.A. Tio, J. van Wijngaarden, P.A. de Graeff, and H. Wesseling. 1992. Effects of converting enzyme inhibitors on coronary flow and myocardial ischemia. J. Cardiovasc. Pharmacol. 19 (Suppl. 5):S134-S139.

57. Lamontagne, D., R. Nadeau, and A. Adam. 1995. Effect of enalaprilat on bradykinin and des-Arg ${ }^{9}$-bradykinin release following reperfusion of the is chaemic rat heart. Br. J. Pharmacol. 115:476-478.

58. Campbell, D.J., A. Kladis, and A.-M. Duncan. 1994. Effects of converting enzyme inhibitors on angiotensin and bradykinin peptides. Hypertension (Dallas). 23:439-449.

59. Minshall, R.D., F. Nakamura, R.P. Becker, and S.F. Rabito. 1995. Characterization of bradykinin $\mathrm{B}_{2}$ receptors in adult myocardium and neonatal rat cardiomyocytes. Circ. Res. 76:773-780.

60. Lindpaintner, K., and D. Ganten. 1991. The cardiac renin-angiotensin system. An appraisal of present experimental and clinical evidence. Circ. Res. 68:905-921.

61. Dzau, V.J., and R.N. Re. 1987. Evidence for the existence of renin in the heart. Circulation. 75 (Suppl. I):I-134-I-136.

62. Sadoshima, J., Y. Xu, H.S. Slayter, and S. Izumo. 1993. Autocrine release of angiotensin II mediates stretch-induced hypertrophy of cardiac myocytes in vitro. Cell. 75:977-984.

63. Aceto, J.F., and K.M. Baker. 1990. [Sar ${ }^{1}$ ]angiotensin II receptor-mediated stimulation of protein synthesis in chick heart cells. Am. J. Physiol. 258: H806-H813.

64. Baker, K.M., and J.F. Aceto. 1990. Angiotensin II stimulation of protein synthesis and cell growth in chick heart cells. Am. J. Physiol. 259:H610-H618.

65. von Lutterotti, N., D.F. Catanzaro, J.E. Sealey, and J.H. Laragh. 1994 Renin is not synthesized by cardiac and extrarenal vascular tissues. A review of experimental evidence. Circulation. 89:458-470.

66. Cohn, J.N. 1995. Structural basis for heart failure. Ventricular remodeling and its pharmacological inhibition [editorial]. Circulation. 91:2504-2507. 